\title{
Quercetin Mitigates Oxidative Stress, Developmental Toxicity and Teratogenic Effects Induced by High-dose Vitamin $D_{2}$ in Zebrafish Embryos
}

\author{
Sukkum Ngullie Chang ${ }^{1}\left(\mathbb{D}\right.$, Hyun Jin Kim $^{2}\left(\mathbb{D}\right.$, Sun Chul Kang ${ }^{1, *}$ (i)
}

${ }^{1}$ Daegu University, Department of Biotechnology, Gyeongsan 38453, Korea

${ }^{2}$ Naturetech Co., Ltd, Chungcheongnam-do 31257, Korea

\section{How to cite}

Chang, S.N., Kim, H.J., Kang, S.C. (2022). Quercetin Mitigates Oxidative Stress, Developmental Toxicity and Teratogenic Effects Induced by High-dose Vitamin $D_{2}$ in Zebrafish Embryos. Turkish Journal of Fisheries and Aquatic Sciences, 22(3), TRJFAS20269. http://doi.org/10.4194/TRJFAS20269

\section{Article History}

Received 04 August 2021

Accepted 25 October 2021

First Online 03 November 2021

\section{Corresponding Author}

Tel.: +82538506569

E-mail: sckang@daegu.ac.kr

\section{Keywords}

High-dose vitamin $D_{2}$

Quercetin

Synergistic effect

Zebrafish embryotoxicity

Teratogenicity

Oxidative stress

Cell death

\begin{abstract}
The aim of the study was to determine the developmental toxicity of high-dose administration of vitamin $D_{2}$ (vit. $D_{2}$ ) and the synergistic effect of vit. $D_{2}$ in co-treatment with quercetin. Zebrafish embryos at $6 \mathrm{hpf}$ were treated with either vit. $D_{2}(1,5,10$ $\mu \mathrm{g} / \mathrm{mL})$ or quercetin $(5,10 \mu \mathrm{g} / \mathrm{mL})$ alone. The results from visual assessment and morphological feature scoring revealed, the occurrence of different morphological abnormalities spiked and aggravated with an increase in vit. $D_{2}$ dose. The percentage of hatching, heartbeats/minute, velocity, body length, and survivability rate was downregulated in high dose vit. $D_{2}$ groups. Subsequently, the production of proinflammatory cytokines and intracellular ROS was upregulated in high-dose vit. $D_{2}$ groups. Contrastingly, in the co-treatment of vit. $D_{2}(5 \mu \mathrm{g} / \mathrm{mL})$ and quercetin $(1,5,10$ $\mu \mathrm{g} / \mathrm{mL}$ ), the occurrence of abnormal morphological characteristics was downregulated and the percentage of survivability rate was significantly increased. The production of inflammatory cytokines, intracellular ROS, and MDA was also observed to be inhibited in co-treatment groups. The important antioxidants such as glutathione and catalase were increased in co-treatment groups. The activity of S-A- $\beta$ gal and apoptosis was downregulated in co-treatment groups. Collectively, quercetin ameliorated the developmental toxicity and teratogenic effects induced by high-dose vit. $D_{2}$.
\end{abstract}

\section{Introduction}

The study on fish is a useful tool for addressing the issues concerning the fundamental processes in the evolution of different types of vertebrates, disease processes, progression, and toxicity study (Choi et al., 2021). In particular, the study on zebrafish (Danio rerio) has become a very important tool for the assessment of drug safety and toxicity studies right from the embryonic developmental defects, teratogenicity, and malformation study. Zebrafish is a tropical fish belonging to the family of Cyprinidae, and it has become a model organism because it is easy to handle and culture and is a cheaper option than the rodent model of study. It also has a high reproduction rate generating hundreds of fertilized eggs that develops rapidly from the embryonic stage into the larval stage. The embryonic development in zebrafish happens transparently allowing it for studying teratogenicity from a newly fertilized egg, formation of a zygotic cell, and organogenesis. Researchers have also been using it for genetic screening such as evaluating the different mutations and the effects it has on the development of organs in the vertebrates (Kamel and Ninov., 2017). Zebrafish studies are also carried out for evaluating a broad spectrum of research that includes disease 
models (Goessling and Sadler, 2015), developmental biology (Roper and Tanguay., 2018), drug discovery (Kithcart and MacRae, 2017), neurobiology (Shams et al., 2017), toxicology study (Yuan et al., 2021) and cancer study (Jeon et al., 2019). Because of the versatility and the substantial area of study it provides, it is now widely accepted that zebrafish is a classical model organism.

Vitamin D is a class of fat-soluble vitamins important for their role in calcium and phosphate metabolism. They are also involved in regulating the immune system and inducing the differentiation of cells (DeLuca., 2004). There are 5 different types of vitamin $D$ and are numbered 2-6. Among these, there are two main forms of vitamin $D$ namely cholecalciferol (vitamin $D_{3}$ ) and ergocalciferol (vitamin $D_{2}$ ). They are almost similar to each other and they differ in the structure only in the side chain where vit. $D_{2}$ has $C 22-C 23$ double bonds and an additional methyl group at C24 (Japelt., 2013). Vitamins are secosteroids that are steroids with broken rings. Vit. $D_{2}$ is produced by fungi and yeast when they are exposed to UVB exposure for 7-dehydrocholesterol (provitamin $\mathrm{D}_{2}$ ), whereas vitamin $\mathrm{D}_{3}$ is produced by UVB exposure of 7-dehydrocholesterol (provitamin $D_{3}$ ) in the skin (Nölle et al., 2018). Studies have been conducted by researchers for vit. $D_{2}$ in a different model system and they include evaluating the role of vit. $D_{2}$ in reverse mutation assays using the TA92, TA1535, TA100, TA1537, TA94, and TA98 strains of Salmonella typhimurium. The results were found to be negative. Another study showed the mutations in thymidine kinase locus in mouse lymphoma cells to be negative for vit. $D_{2}$. Mouse Bone Marrow Cells for vit. $D_{2}$ and vit. $D_{3}$ was also reported to be negative (Ishidate et al., 1984). The assays for vitamin $D_{2}$ carcinogenicity in the literature take the place as non-carcinogenic for a mouse in Carcinogenic Potency Database (CPDB) (https://toxnet.nlm.nih.gov/cpdb/) and QSAR Toolbox. The oral toxicity and LD50 of vit. $D_{2}$ in mice was found to be around $23.7 \mathrm{mg} / \mathrm{kg}$ and $10 \mathrm{mg} / \mathrm{kg}$ for rats (Tugcu et al., 2019), whereas the lethal dose in dogs was found to be $13 \mathrm{mg} / \mathrm{kg}$. However, the developmental toxicity and teratogenic study of vit. $D_{2}$ in zebrafish embryos and larvae has not been evaluated before.

We used quercetin, a plant flavonoid having numerous multi-therapeutic properties to evaluate its protective and synergistic effects when administered in cotreatment with vit. $D_{2}$. The word Quercetin comes from the Latin word quercous, meaning "oak" deriving from quercetum (oak forest) after "Quercus" and the name was coined in 1857. Quercetin is found in around 20 different kinds of fruits and vegetables such as apples, berries, onions, broccoli, etc. Quercetin is well known to possess antioxidant activity, anti-inflammatory, antibacterial, antiviral as well as anticancer activity (Sultana and Anwar., 2008). The structure of quercetin is composed of the ketocarbonyl group and the oxygen present in the first carbon can generate acids and salts. One of the reasons why quercetin has a very strong antioxidant activity is because of the presence of the phenolic hydroxyl group and doubled bonds. It also has a dihydroxy group in between the $\mathrm{A}$ ring, O-dihydroxy group B, C ring C2, C3 double bond, and also a 4carbonyl (Yang et al., 2020). However, at higher doses, quercetin has also been found to be toxic and lead to carcinogenicity as observed from male and female rats (Harwood et al., 2007). Evaluation for the oral administration of quercetin showed the $L_{50}$ to be 161 $\mathrm{mg} / \mathrm{kg}$ for rats and $159 \mathrm{mg} / \mathrm{kg}$ in mice. LD $_{50}$ dose intravenous injection showed to be at $18 \mathrm{mg} / \mathrm{kg}$ in mouse model whereas, subcutaneous administration showed $\mathrm{LD}_{50}$ at $97 \mathrm{mg} / \mathrm{kg}$ (Harishkumar., 2019). The toxicity of quercetin has been studied before by researchers, but the synergistic effects of quercetin in combination with drugs inducing toxicity have not been studied before. This paper aimed to evaluate the toxic effects as well as the protective effects quercetin might have on the development of zebrafish embryos. From our recent study, we were able to show that quercetin was able to inhibit or slow down the process of vit. $\mathrm{D}_{2}$ degradation is triggered by high temperature and $\mathrm{pH}$ (Chang et al., 2021). Hence, we wanted to evaluate their synergistic effects. Our study was designed to assess the concentration range at which vit. $D_{2}$ becomes teratogenic and toxic to the developing zebrafish embryo and to study the role of quercetin in possibly neutralizing the toxic effects of high-dose vit. $D_{2}$ on zebrafish embryos.

\section{Materials and methods}

\section{Chemicals}

Vitamin $D_{2}$ (ergocalciferol), quercetin, acridine orange, $\mathrm{H}_{2}$ DCFDA, ethidium bromide, was purchased from Sigma Aldrich. All other chemicals and reagents utilized in this study were of analytical grade.

\section{Zebrafish culture and vitamin $D_{2}$ developmental toxicity study}

Wild type Danio rerio zebrafish ( $A B$ strain) were allowed to grow and reproduce under healthy environmental conditions $\left(28^{\circ} \mathrm{C}\right.$ and $80 \%$ humidity) as per the previously published paper (Chang et al., 2020; Dey et al., 2021; Vasamsetti et al., 2020). Zebrafish were adjusted to $14 \mathrm{~h}$ light and $10 \mathrm{~h}$ dark cycle. The next day, fertilized eggs were collected within 6 hours postfertilization (hpf). Healthy zebrafish embryos ( $n=$ 20/group) were properly maintained at a suitable temperature $\left(28^{\circ} \mathrm{C}\right)$ in $\mathrm{E} 3$ media containing $(0.17 \mathrm{mM}$ $\mathrm{KCl}, 5 \mathrm{mM} \mathrm{NaCl}, 0.16 \mathrm{mM} \mathrm{MgSO}_{4}, 0.4 \mathrm{mM} \mathrm{CaCl}_{2}, 0.1 \%$ methylene blue). Treatment of vit. $D_{2}(1,5,10 \mu \mathrm{g} / \mathrm{ml})$ and quercetin (5 and $10 \mu \mathrm{g} / \mathrm{ml})$ and vit. $\mathrm{D}_{2}(5 \mu \mathrm{g} / \mathrm{ml})+$ quercetin $(1,5,10 \mu \mathrm{g} / \mathrm{ml})$ was started from 6 hours postfertilization (hpf) till $120 \mathrm{hpf}$.

All the dead embryos and larvae during the experiment were removed and discarded every $12 \mathrm{~h}$. Images were 
collected everyday throughout the experimental period to check for abnormalities. The different groups used for the zebrafish embryotoxicity study are listed above. All the experiments procedures were performed according to the guidelines for animal care and handling norms approved by the Institutional Animal Care and Use Committee of Daegu University, Gyeongbook, South Korea (Number: Lab-2021E-164709).

\begin{tabular}{ll}
\hline Groups & Dosage concentration $(\mu \mathrm{g} / \mathrm{ml})$ \\
\hline Control & no treatment \\
\hline & $1 \mu \mathrm{g} / \mathrm{ml}$ \\
Vitamin $D_{2}$ & $5 \mu \mathrm{g} / \mathrm{ml}$ \\
& $10 \mu \mathrm{g} / \mathrm{ml}$ \\
Quercetin & $5 \mu \mathrm{g} / \mathrm{ml}$ \\
& $10 \mu \mathrm{g} / \mathrm{ml}$ \\
Co-treatment groups & $5 \mu \mathrm{g} / \mathrm{ml} \mathrm{Vit.} D_{2}+1 \mu \mathrm{g} / \mathrm{ml}$ Quercetin \\
& $5 \mu \mathrm{g} / \mathrm{ml} \mathrm{Vit.} D_{2}+5 \mu \mathrm{g} / \mathrm{ml}$ Quercetin \\
Vitamin $D_{2}+$ Quercetin & $5 \mu \mathrm{g} / \mathrm{ml} \mathrm{Vit.} D_{2}+10 \mu \mathrm{g} / \mathrm{ml}$ Quercetin \\
\hline
\end{tabular}

\section{Measurement of heart rate}

The measurement of the heart rate of zebrafish larvae was performed at $120 \mathrm{hpf}$. Briefly, all the larvae to be analyzed were anesthetized using $0.016 \%(\mathrm{w} / \mathrm{v})$ tricaine (ethyl 3-aminobenzoate methane sulfonate, Sigma) and the heart rate was counted for $1 \mathrm{~min}$.

\section{Swimming behavior evaluation}

Zebrafish larvae at $120 \mathrm{hpf}$ were used for evaluating the swimming behavior after being exposed to different concentrations of vit. $D_{2}(1,5,10 \mu \mathrm{g} / \mathrm{ml})$ and quercetin $(5$ and $10 \mu \mathrm{g} / \mathrm{ml})$ and vit. $\mathrm{D}_{2}(5 \mu \mathrm{g} / \mathrm{ml})+$ quercetin $(1,5$, $10 \mu \mathrm{g} / \mathrm{ml})$, the larvae were subjected to behavioral tests. Firstly, 10 different larvae were rinsed twice in fresh water. They were then placed in 24-well plates with 1 $\mathrm{mL}$ fish water and assigned with one larva/ well and incubated for $30 \mathrm{~min}$ at $28^{\circ} \mathrm{C}$. Finally, to analyze the movement of the zebrafish larvae, we used Zebra Lab software (Viewpoint, France) and evaluated the movement for $10 \mathrm{~min}$.

\section{$\mathrm{H}_{2}$ DCFDA staining}

For estimating the production of free radicals and accumulation of reactive oxygen species (ROS) in zebrafish larvae, we followed the previously published paper from our research group (Chang et al., 2020). Zebrafish were treated with varying concentrations of vit. $D_{2}$ and quercetin starting from $6 \mathrm{hpf}-120 \mathrm{hpf}$. After $120 \mathrm{hpf}$ treatment with different doses of vit. $\mathrm{D}_{2}$ and quercetin, the zebrafish larvae were exposed to $\mathrm{H}_{2}$ DCFDA at a dose of $10 \mu \mathrm{g} / \mathrm{mL}$ and DAPI $(1 \mu \mathrm{g} / \mathrm{mL})$ for 1 hour at $37^{\circ} \mathrm{C}$ in complete darkness. After incubation, the zebrafish larvae were washed with PBS and observed under the microscope for the production of ROS. The intensity of the green fluorescence was determined as the final concentration of ROS and was analyzed using an Olympus BX50 fluorescence microscope at 10x magnification.

\section{Estimation of cytokines and oxidative stress from zebrafish tissue homogenates}

The zebrafish larvae homogenates were used for experimenting. For measuring malondialdehyde, we followed the manufacturer's protocol (Abcam, Cambridge, CB2 OAX, UK). For detection of inflammation iNOS (\#13120, Cell Signaling), and TNF- $\alpha$ (\#6945, Cell Signaling) we used sandwich enzyme-linked immunosorbent assay. All the experiments were strictly carried out in triplicates and the absorbance was taken on a microtiter plate reader at $450 \mathrm{~nm}$ (Bio-Tek Instrument Co., WA, USA). For detection of antioxidant enzymes such as catalase and Glutathione, we used the Cayman assay kit and followed the manufacturer's protocol.

\section{Senescence-associated $\boldsymbol{\beta}$-galactosidase activity}

For determining Senescence associated-betagalactosidase (SA- $\beta$-gal) activity, we followed the manufacturer's protocol of the X-gal staining method (Sigma) and from the previously published manuscript (Da Silva-Álvarez et al., 2020). After treatment at 120 hpf, zebrafish larvae were washed twice with $1 \mathrm{ml}$ of PBS per well/plate. Next, add $1.5 \mathrm{ml}$ per well of fixation buffer and incubate the plate for 15 minutes at room temperature. During the fixation process prepare the staining mixture as described in the preparation instructions. Rinse 3 times with $1 \mathrm{ml}$ of PBS per well/plate. Later, add $1 \mathrm{ml}$ of the staining mixture to each well. Incubate at $37^{\circ} \mathrm{C}$ without $\mathrm{CO}_{2}$ until the cells are stained blue ( 2 hours to overnight). Seal the plate with parafilm to prevent it from drying out. After the completion, wash the plates with PBS and observe the zebrafish larvae under the bright field microscope and count the number of blue-stained cells and larvae expressing beta galactoside.

\section{Acridine Orange-Ethidium bromide staining}

For the analysis of cell death and apoptotic events happening in zebrafish larvae (Alvarez et al., 2014; Chang et al., 2021a), the surviving larvae of $6 \mathrm{dpf}$ and controls were transferred to acridine Orange (AO)/ethidium Bromide (EB) solution; both at $0.5 \mathrm{mg} / \mathrm{ml}$ for 30 minutes at $37^{\circ} \mathrm{C}$. The $A O$ pervades all living cells and provides a green color to the core, unlike EB, which is only incorporated into the cell when this has lost membrane integrity, giving a red color to the nucleus. After labeling time, the larvae were observed under the BX50 Olympus fluorescence microscope. Through the program of ImageJ, the analysis of the areas from green 
fluorescence was performed, highlighting areas of tissue with living cells and tissue areas with permeable cell EB. The use of the image analysis program ImageJ allowed to estimate the fluorescence intensity in different regions of the larvae, under control and treated conditions.

\section{Statistical analysis}

The data presented in this manuscript were conducted using GraphPad Prism software (version 5). The data are expressed here are the means \pm standard error (SE). The significant differences between the mean values were analyzed using one-way analysis of variance (ANOVA) with Tukey's test comparing all pairs of columns, where $*$ represents $p$-values $<0.05, * *$ represents $p$-values < 0.01 , and $* * *$ represents $p$-values $<0.001$.

\section{Results and Discussion}

\section{Evaluation of the developmental toxicity of vitamin $D_{2}$ on zebrafish embryo}

Zebrafish eggs were collected after mating and were treated with varying concentrations of high-dose vit. $D_{2}$ $(1,5$ and $10 \mu \mathrm{g} / \mathrm{mL})$ or quercetin $(5$ and $10 \mu \mathrm{g} / \mathrm{mL})$ to estimate the developmental toxicity and lethality. The structure of vit. $D_{2}$ and quercetin are shown in Supplementary Fig. 1. Treatment started as early as 6 hpf (hours post fertilization) and continued till $120 \mathrm{hpf}$. The hatching rate observed after treatment with vit. $\mathrm{D}_{2}$ $(1,5$ and $10 \mu \mathrm{g} / \mathrm{mL})$ were found to be 75,70 , and $66.66 \%$, whereas for quercetin ( 5 and $10 \mu \mathrm{g} / \mathrm{mL}$ ), the hatching rate was found to be $90 \%$ and $80 \%$ in comparison to no treatment control group that had a hatching rate of $90 \%$ (Figure $2 \mathrm{~A}$ ). Next, we evaluated the heartbeat/min of zebrafish larvae at $120 \mathrm{hpf}$. We observed a drop in the heartbeat/min with increasing concentration of vit. $D_{2}$. The heartbeat per minute for different concentrations of vit. $\mathrm{D}_{2}(1,5$ and $10 \mu \mathrm{g} / \mathrm{mL})$ were 165, 163 and 142.33 in comparison to control (176 heartbeat/min), whereas there were no significant changes in the quercetin ( 5 and $10 \mu \mathrm{g} / \mathrm{mL}$ ) groups having 170 and 165 heartbeats/min (Figure 2B). Subsequently, over a 6-day period we evaluated zebrafish embryos for abnormalities every day after drug treatment. The different abnormalities observed from morphological images were curved tail, coagulation, yolk edema, pericardial edema, hydrocephalus and curved fin, which was significantly higher in vit. $D_{2}$ (Figure 1 ). The percentage of the occurrence of different abnormalities in the head, tail, yolk sac, and pericardia regions of the

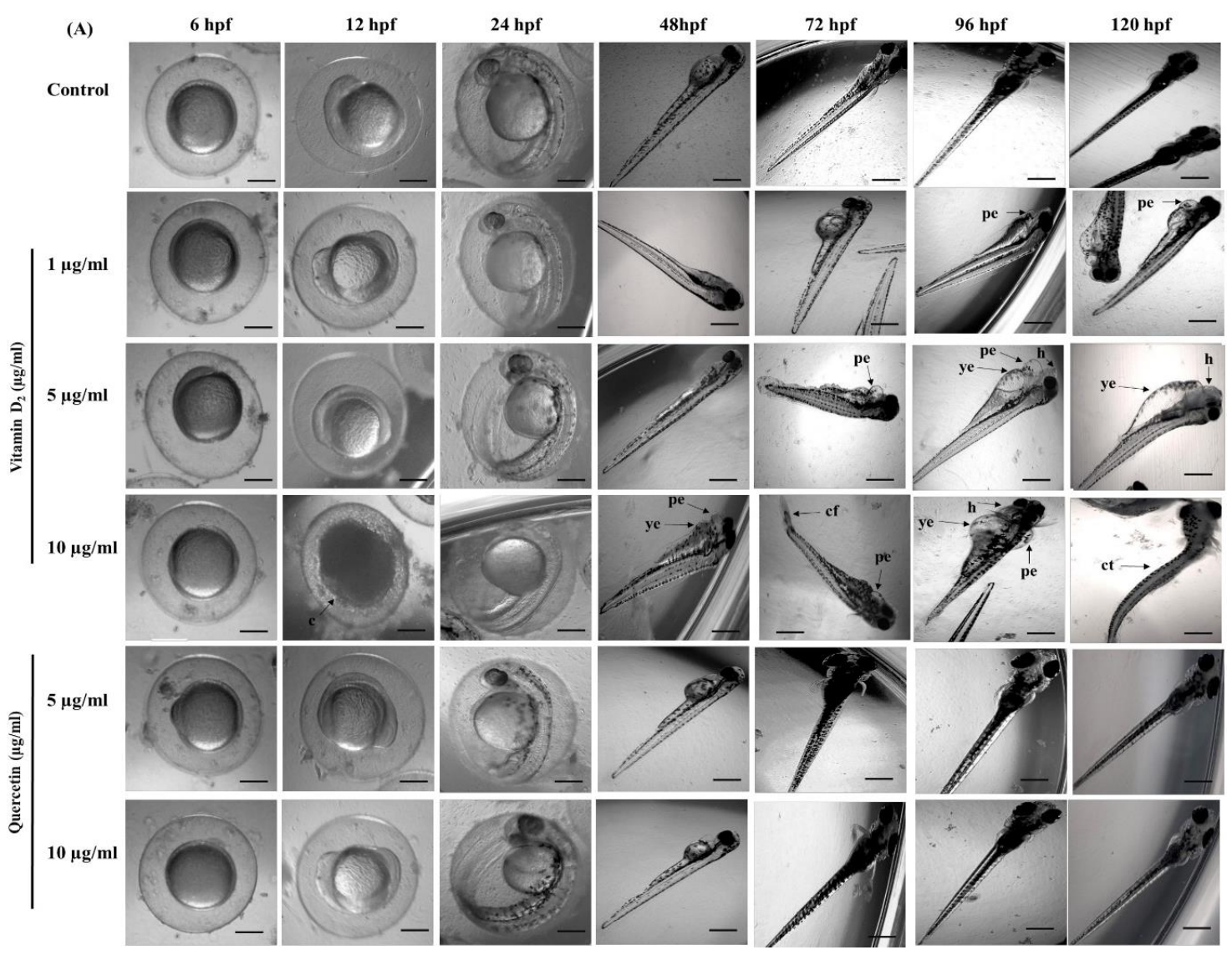

Figure 1. Observation of morphological deformities at different time points after treatment with high-dose vit. $\mathrm{D}_{2}(1,5$ and 10 $\mu \mathrm{g} / \mathrm{ml}$ ) or quercetin $(5$ and $10 \mu \mathrm{g} / \mathrm{ml})$. C- coagulation, ye- yolk edema, pe-pericardial edema, ct-curved tail, cf-curved fin, hhydrocephalus. ( $n=20 /$ group). 


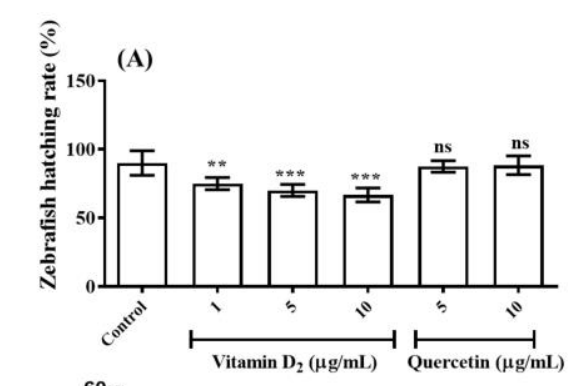

(B)

(C)
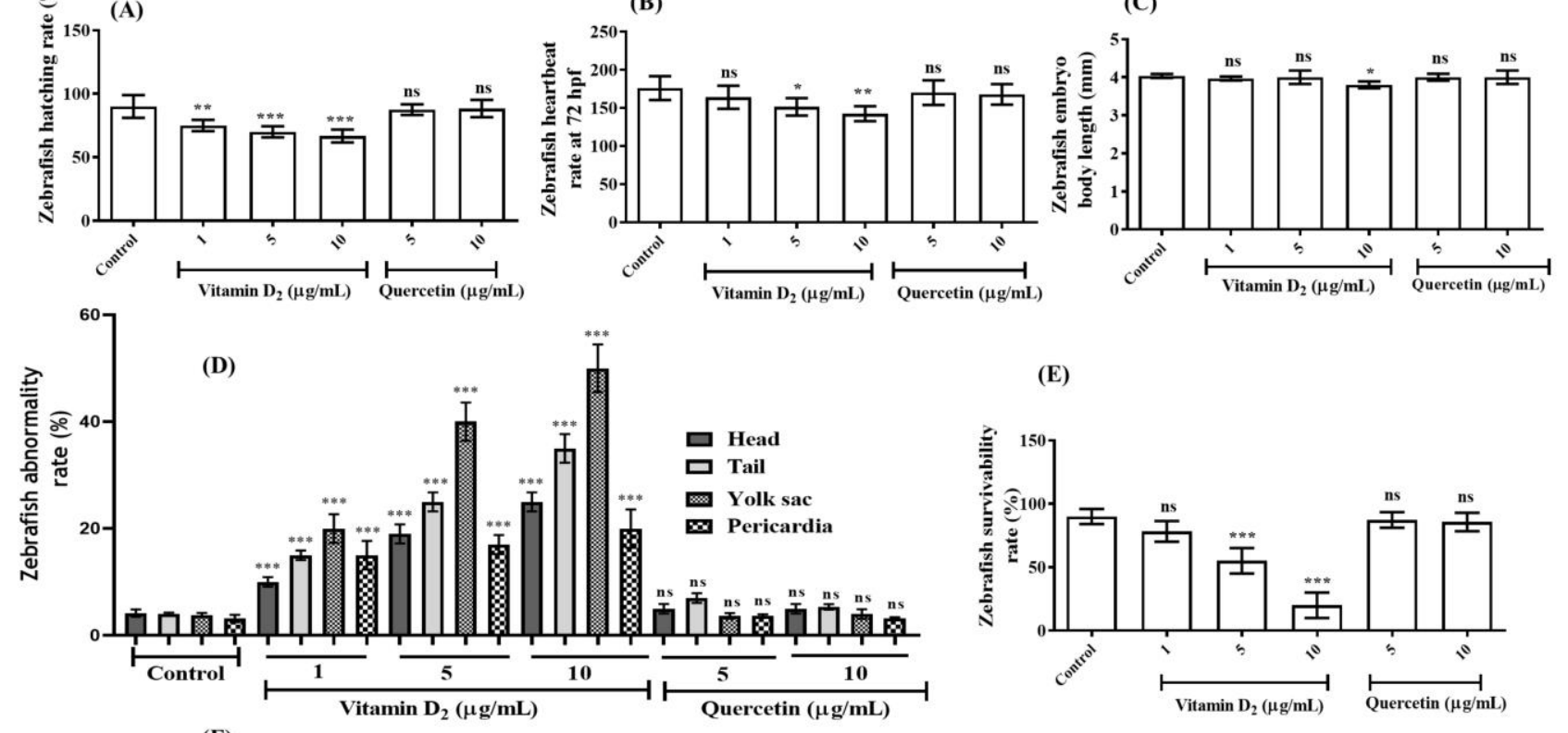

(E)

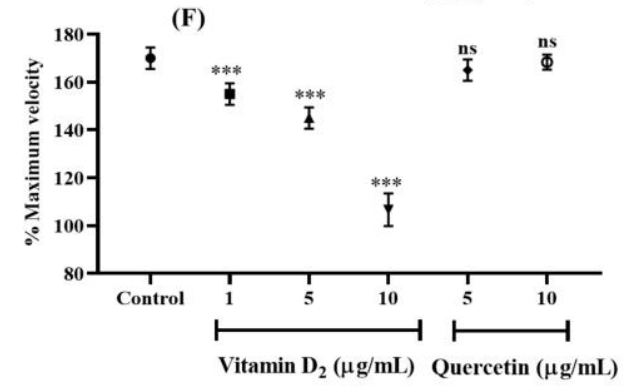

Figure 2. Evaluation of different parameters after treatment with vit. $D_{2}(1,5$ and $10 \mu \mathrm{g} / \mathrm{ml})$ or quercetin $(5$ and $10 \mu \mathrm{g} / \mathrm{ml})$ ( $\left.\mathrm{n}=20 / \mathrm{group}\right)$ (A) Percentage of zebrafish hatching rate (B) Zebrafish heartbeat/min at $72 \mathrm{hpf}$ (hours post fertilization) (C) Estimation of average zebrafish body length at $120 \mathrm{hpf}$ (D) Different morphological abnormality percentage of zebrafish embryos after treatment with highdose vit. $D_{2}(1,5$ and $10 \mu \mathrm{g} / \mathrm{ml})$ or quercetin $(5$ and $10 \mu \mathrm{g} / \mathrm{ml})$ (E) Percentage of zebrafish survivability rate after treatment (F) Percentage of zebrafish maximum velocity. The data that are represented here are the means \pm S.D. where significant difference is indicated as $* p<0.05, * * p<0.01, * * * p<0.001$ and ns (non-significant), control vs vit. $\mathrm{D}_{2}$ group, control vs Quercetin group, control vs vit. $D_{2}+$ quercetin group. Statistical significance analysis was carried out through a one-way analysis of variance (ANOVA) prism.

embryo is shown in Figure 2D. Our next evaluation was performed after continuous treatment with vit. $\mathrm{D}_{2}$ for $120 \mathrm{hpf}$. The average body length of the respective groups was found to be: control $(4.03 \mathrm{~mm})$, vit. $\mathrm{D}_{2}(1,5$ and $10 \mu \mathrm{g} / \mathrm{mL}) 3.96,4$ and $3.8 \mathrm{~mm}$, whereas for quercetin $(5$ and $10 \mu \mathrm{g} / \mathrm{mL}$ ) the average body length was 4 and $4.1 \mathrm{~mm}$ (Figure 2C). Finally, we evaluated the survivability percentage rate from $120 \mathrm{hpf}$ larvae. The control group had a survivability rate of $93 \%$, whereas vit. $D_{2}(1,5$ and $10 \mu \mathrm{g} / \mathrm{mL})$ showed survivability percentage rate of $78.33,55$, and $20 \%$. The mortality rate of zebrafish larvae rose to $80 \%$ on embryos treated with $10 \mu \mathrm{g} / \mathrm{mL}$ of vit. $D_{2}$. Whereas, we didn't observe any significant difference in the survivability rate of zebrafish larvae treated with quercetin. Quercetin at 5 and $10 \mu \mathrm{g} / \mathrm{mL}$ showed a significant survivability rate of 90\% and $85.66 \%$ (Figure 2E). There was also a dosedependent downregulation of larval motility in highdose vit. $D_{2}$ (Figure 2F). After analyzing the abovementioned result, we decided on the concentration of vit. $D_{2}$ at $5 \mu \mathrm{g} / \mathrm{mL}$ since it showed a survivability percentage of $55 \%$. We proceeded with the next study for the synergistic effects of vit. $D_{2}$ in combination with varying doses of quercetin on developing zebrafish embryos.

\section{Quercetin ameliorates high-dose vitamin $D_{2}$ induced developmental toxicity on zebrafish embryo}

We evaluated the synergistic effect of vit. $D_{2}$ and quercetin after evaluating the toxicity of high-dose vit. $D_{2}$ having survivability of $55 \%$ at a concentration range of $5 \mu \mathrm{g} / \mathrm{mL}$ (Figure $2 \mathrm{E}$ ). We decided to use this dosage group for evaluating the synergistic effect quercetin might exert in reducing the malformations and survivability percentage. The hatching rate was significantly increased as observed for the combinational treatment group of high-dose vit. $D_{2}(5$ $\mu \mathrm{g} / \mathrm{mL})+$ quercetin $(1,5$ and $10 \mu \mathrm{g} / \mathrm{mL}$ ) having a hatching rate of $75,76.66,90 \%$ in comparison to no treatment group with a hatching rate of $90 \%$ (Figure $3 \mathrm{~B}$ ). Next, we evaluated the heartbeat/minute ratio on 120 hpf zebrafish embryos to see a significant enhancement in the heartbeat ratio similar to control in vit. $D_{2}$ and quercetin treatment groups in a dose-dependent manner. The calculated heartbeat/min ratio for high- 

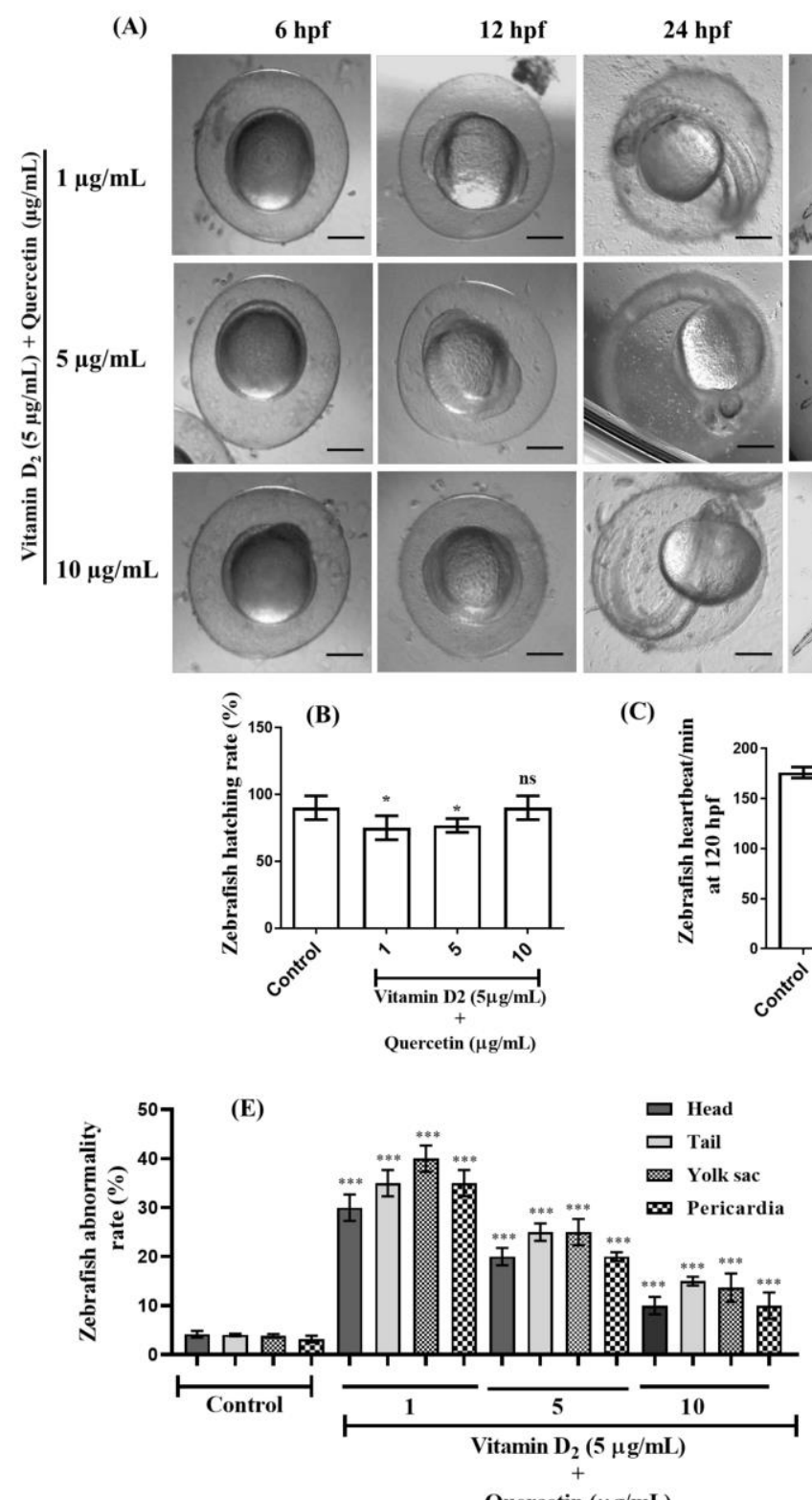

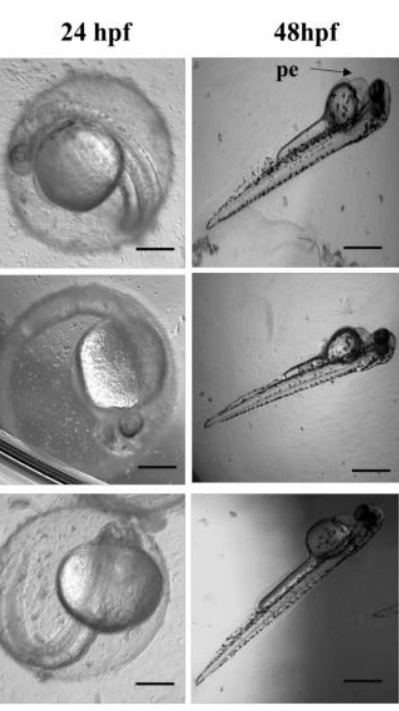

(C)

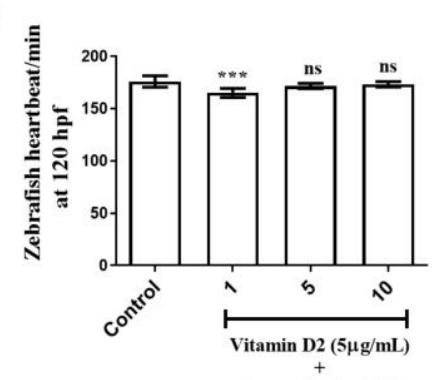

Quercetin $(\mu \mathrm{g} / \mathrm{mL})$

(F)

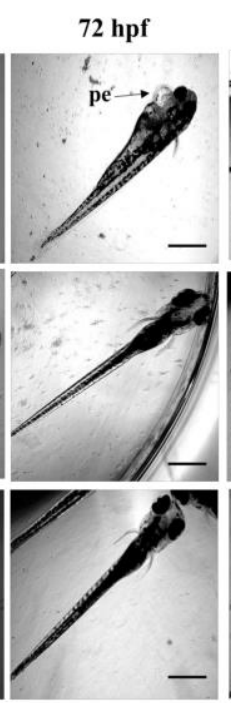

(D)
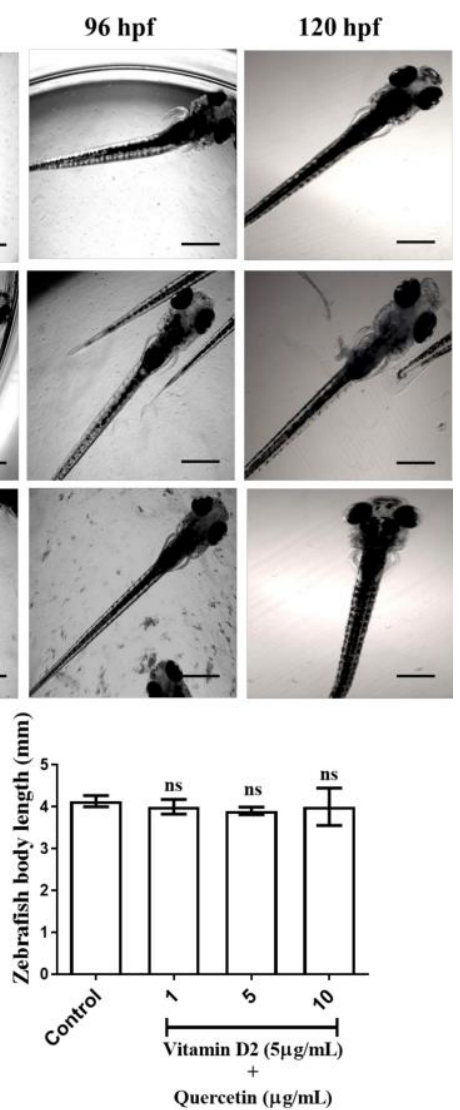

(G)
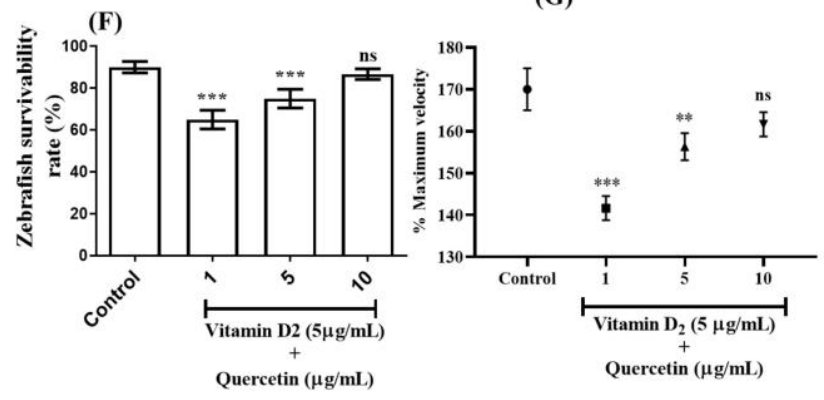

Figure 3. Evaluation of different parameters after co-treatment with vit. $D_{2}(5 \mu \mathrm{g} / \mathrm{ml})$ and quercetin $(1,5$ and $10 \mu \mathrm{g} / \mathrm{ml})(\mathrm{n}=20 / \mathrm{group})$ (A) Observation of morphological deformities at different time points after co-treatment with vit. $\mathrm{D}_{2}(5 \mu \mathrm{g} / \mathrm{ml})$ and quercetin $(1,5$ and $10 \mu \mathrm{g} / \mathrm{ml}$ ). pe- pericardial edema. (B) Percentage of zebrafish hatching rate (C) Evaluation of heartbeat/min at $72 \mathrm{hpf}$ (D) Estimation of average zebrafish body length at $120 \mathrm{hpf}$ (E) Different morphological abnormality percentage of zebrafish embryos after treatment with high-dose vit. $\mathrm{D}_{2}(1,5$ and $10 \mu \mathrm{g} / \mathrm{ml})$ or quercetin $(5$ and $10 \mu \mathrm{g} / \mathrm{ml})$ (F) Percentage of zebrafish survivability rate (G) Percentage of maximum zebrafish velocity. The data that are represented here are the means \pm S.D. where significant difference is indicated as $* p<0.05,{ }^{* *} p<0.01,{ }^{* * *} p<0.001$ and ns (non-significant), where control vs vit. $\mathrm{D}_{2}$ group, control vs Quercetin group, control vs vit. $D_{2}+$ quercetin group. Statistical significance analysis was carried out through a one-way analysis of variance (ANOVA) prism.

dose vit. $\mathrm{D}_{2}(5 \mu \mathrm{g} / \mathrm{mL})+$ quercetin $(1,5$ and $10 \mu \mathrm{g} / \mathrm{mL})$ were $165,171.66$ and 173.33 in comparison to control 176 heartbeats/min (Figure $3 \mathrm{C}$ ). The percentage of the occurrence of morphological malformations was calculated as per the abnormality observed in the head, tail, yolk sac, and pericardia, where quercetin was able to significantly reduce the effects of malformations in the larvae induced by treatment with high-dose vit. $D_{2}$. The aberrations observed from morphological images were coagulation after $24 \mathrm{~h}$ treatment, curved fin, curved tail, yolk edema, pericardial edema, hydrocephalus (Figure 3A). The percentage of abnormality in head, tail, yolk sac and pericardia was reduced significantly in co-treatment groups (Figure $3 \mathrm{E}$ ). We observed no significant difference in the body length of zebrafish embryos showing 4, 4.1 and $4.2 \mathrm{~mm}$ for combinational treatment and $4.13 \mathrm{~mm}$ for control groups (Figure 3D). Finally, we evaluated the survivability of zebrafish embryos after combinational treatment at $120 \mathrm{hpf}$. The results revealed that quercetin was able to significantly reduce the toxicity and mortality of embryos caused by high concentration treatment of vit. $D_{2}$. The survivability rate observed for high-dose vit. $\mathrm{D}_{2}(5 \mu \mathrm{g} / \mathrm{mL})+$ quercetin $(1,5$ and 10 


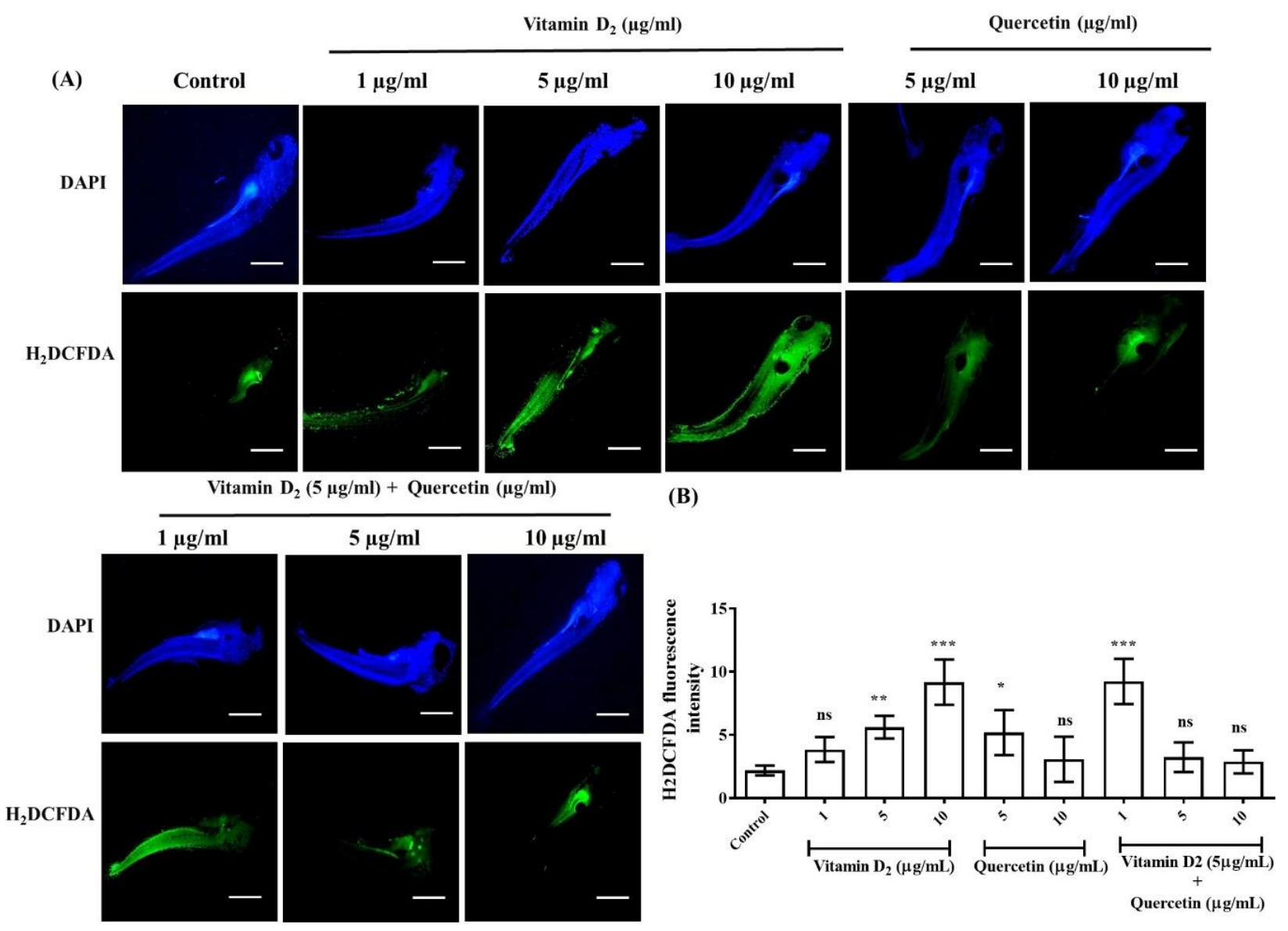

Figure 4. Estimation of ROS generation after treatment with vit. $D_{2}(1,5$ and $10 \mu \mathrm{g} / \mathrm{ml})$, quercetin $(5 \mathrm{and} 10 \mu \mathrm{g} / \mathrm{ml})$ or co-treatment with high-dose vit. $\mathrm{D}_{2}(5 \mathrm{\mu g} / \mathrm{ml})$ and quercetin $(1,5$ and $10 \mu \mathrm{g} / \mathrm{ml})(\mathrm{A}) \mathrm{H}_{2}$ DCFDA staining at $120 \mathrm{hpf}$ for different treatment groups. Green fluorescence: production of ROS; blue fluorescence: staining of the nucleus (B) Fluorescence intensity of $\mathrm{H}_{2}$ DCFDA staining for vit. $D_{2}(1,5$ and $10 \mu \mathrm{g} / \mathrm{ml})$, quercetin $(5$ and $10 \mu \mathrm{g} / \mathrm{ml})$ treatment groups. The data that are represented here are the means \pm S.D. where significant difference is indicated as $* p<0.05, * * p<0.01, * * * p<0.001$ and ns (non-significant), where control vs vit. $D_{2}$ group, control vs Quercetin group, control vs vit. $D_{2}+$ quercetin group. Statistical significance analysis was carried out through a one-way analysis of variance (ANOVA) prism.

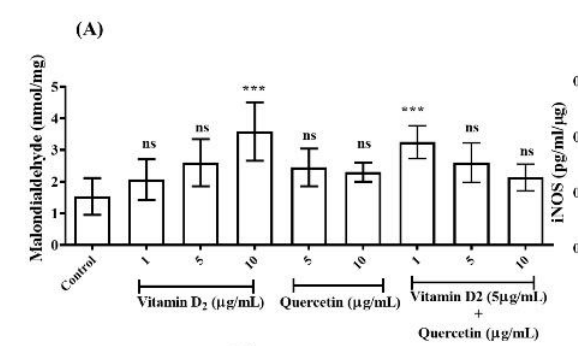

(D)

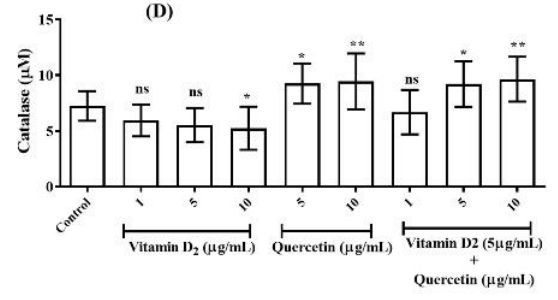

(B)

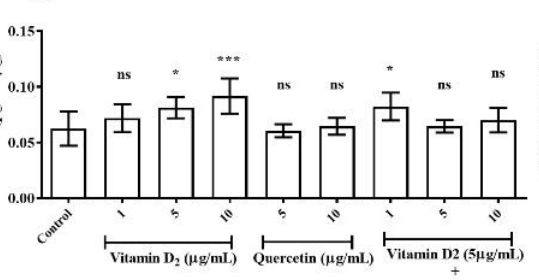

(E)
(C)

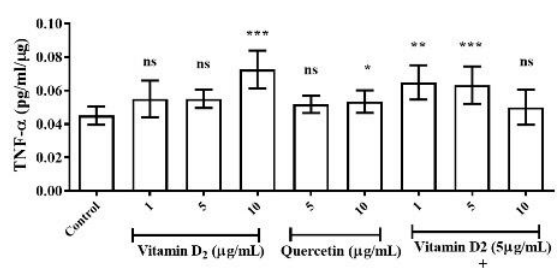

Quercetin $(\mu g / m L)$

Figure 5. Estimation of (A) MDA assay (B) iNOS (C) TNF- $\alpha$ (D) Catalase (E) Glutathione assay. The data that are represented here are the means \pm S.D. where significant difference is indicated as $* p<0.05, * * p<0.01, * * * p<0.001$ and ns (non-significant), where control vs vit. $D_{2}$ group, control vs Quercetin group, control vs vit. $D_{2}+$ quercetin group. Statistical significance analysis was carried out through a one-way analysis of variance (ANOVA) prism. 
$\mu \mathrm{g} / \mathrm{mL}$ ) were 65,75 and $86.66 \%$ in comparison to control group having a survivability rate of $90 \%$ (Figure $3 F$ ). The motility of zebrafish larvae was also significantly better in co-treatment groups (Figure. 3G). We observed that quercetin was able to significantly enhance the development of zebrafish embryo in combination with vit. $D_{2}$. The hatching rate was fastened upon the combinational treatment which increased dosedependently. We also observed that the heartbeat ratio was normalized and similar to control groups in a dosedependent manner. The formation of major organs was also enhanced with a drastic reduction in the morphological abnormality rate. Conclusively, we observed that combinational treatment of vit. $D_{2}$ and quercetin had a synergistic effect by boosting the development of zebrafish embryos.

Quercetin equilibrates high-dose vitamin $D_{2}$ induced oxidative stress and enhanced antioxidant enzymes in zebrafish larvae

Oxidative stress is one of the major mechanism for toxicity in vitro and in vivo. The changes observed in the antioxidant enzymes are important for understanding the effect of drug-induced toxicity on redox homeostasis (Thirumurthi et al., 2021). In order to analyze the production of intracellular ROS, we performed $\mathrm{H}_{2}$ DCFDA staining. They are fluorogenic dyes widely used for measuring hydroxyl, peroxyl, and other reactive oxygen species (ROS) activity within the cells or in the tissue. The observation from our staining images revealed that treatment with vit. $D_{2}$ alone had highly expressed fluorescence which increased in a dose-dependent manner as an indication for the presence of more free radicals. Quercetin treatment also revealed that 5 $\mu \mathrm{g} / \mathrm{mL}$ had a higher expression of green fluorescence in comparison with control (Figure 4A). Finally, the combinational treatment of vit. $\mathrm{D}_{2}(5 \mu \mathrm{g} / \mathrm{mL})+$ quercetin $(1,5$ and $10 \mu \mathrm{g} / \mathrm{mL})$ showed that quercetin was able to significantly neutralize and reduce the expression of free radicals and creating a sort of balance in the embryonic zebrafish larvae (Figure 4B). The fluorescence intensity was calculated from the respective images of the different treatment groups revealing that quercetin had a synergistic effect when treated in combination with vit. $D_{2}$ and was able to downregulate the expression of ROS. We also performed a malondialdehyde biochemical assay for excessive lipid peroxidation and observed a dose-dependent reduction. The expression of MDA for vit. $D_{2}(1,5$ and $10 \mu \mathrm{g} / \mathrm{mL})$ was $2,2.6$ and 3.58 $\mathrm{nmol} / \mathrm{mg}$, whereas quercetin $(5$ and $10 \mu \mathrm{g} / \mathrm{mL}$ ) was 2.45 and $2.3 \mathrm{nmol} / \mathrm{mg}$. The MDA concentration observed for high-dose vit. $D_{2}(5 \mu \mathrm{g} / \mathrm{mL})+$ quercetin $(1,5$ and 10 $\mu \mathrm{g} / \mathrm{mL}$ ) were 3.25, 2.6 and $2.13 \mathrm{nmol} / \mathrm{mg}$ (Fig. 5A). We did not observe a significant difference in the concentration and expression of iNOS and TNF- $\alpha$ concentration (Fig. 5B, C). However, quercetin treatment was able to upregulate the concentration of catalase and GSH. The concentration of catalase for vit.
$\mathrm{D}_{2}(1,5$ and $10 \mu \mathrm{g} / \mathrm{mL})$ were $5.95,5.53$ and $5.25 \mu \mathrm{M}$, whereas quercetin $(5$ and $10 \mu \mathrm{g} / \mathrm{mL}$ ) were 9.26 and 9.4 $\mu \mathrm{M}$. The concentration of high-dose vit. $\mathrm{D}_{2}(5 \mu \mathrm{g} / \mathrm{mL})+$ quercetin $(1,5$ and $10 \mu \mathrm{g} / \mathrm{mL})$ were $6.7,9.12$ and 9.65 $\mu \mathrm{M}$ in comparison to control (7.25 $\mu \mathrm{M}$ ) (Fig. 5D). We also observed a slight increase in the GSH concentration in higher doses of quercetin treatment groups (Fig. 5E). We conclude from this above finding that quercetin was able to alleviate high-dose vit. $D_{2}$ induced oxidative stress.

\section{Quercetin treatment reduced expression of S-A- $\beta$ - gal in high-dose vitamin $D_{2}$ treated zebrafish embryos}

There have been reports from several different studies for the occurrence of cellular senescence during the development of tissues in different types of birds, amphibians, and mammals. The presence of cellular senescence during the development of zebrafish embryos has also been reported (Villiard et al., 2017). One of the key phenotypes of senescence includes the senescence associated-beta galactosidase activity and these senescent cells produce high levels of reactive oxygen species (ROS) and also contain elevated levels of DNA damage, which was observably seen in zebrafish larvae at $120 \mathrm{hpf}$. Our results revealed that S-A- $\beta$ - gal activity and expression were upregulated in all the vit. $D_{2}$ treatment groups in a dose-dependent manner and was prominently visible in the yolk sac regions and extending to the intestines, esophagus, regions of the brain and spinal cord. S-A- $\beta$ - gal activity was also present in quercetin only treatment groups. The $S-A-\beta$ gal activity and expression were significantly downregulated in combinational treatment groups of high-dose vit. $D_{2}+$ quercetin as evidently observed and visibly absent from the spinal cord and lesser expression in other regions of the zebrafish larvae indicating the positive effects of combinational treatment on zebrafish larvae (Figure 6A).

\section{Quercetin alleviates high-dose vitamin $D_{2}$ induced zebrafish larval cell death}

Drug-induced toxicity and cell death have been well documented and studied in zebrafish larvae (Li et al., 2018; Alvarez et al., 2014). Cell death usually occurs through apoptosis and necrosis. Apoptosis cell death involves a genetically determined elimination of damaged cells from the tissues and the body of the organism (Chang et al., 2021b). Many drugs used for the treatment of different types of cancer result in DNA damage which leads to apoptotic cell death. Some hormones, such as corticosteroids also lead to apoptotic cell death in some cell types. Similarly, vit. $D_{2}$ has been shown to induce apoptotic cell death on HL-60 cells. Their study showed that DNA fragmentation occurred in the cells at a concentration of $100 \mu \mathrm{M}$ which is a typical hallmark of apoptosis. To confirm if a high-dose vit. $D_{2}$ could trigger apoptosis, we performed a dual acridine 


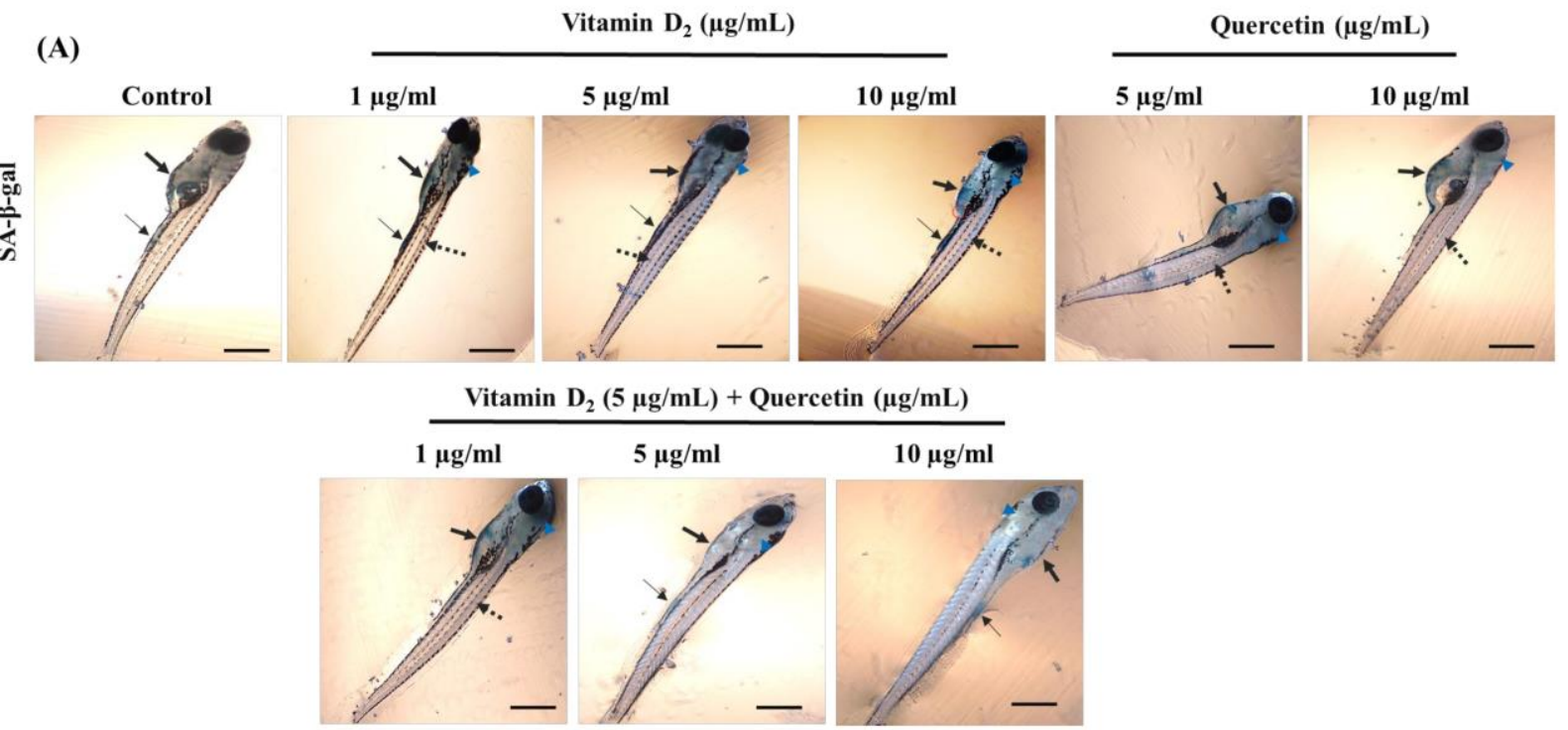

Figure 6: (A) Estimation of S-A- $\beta$ - gal activity after treatment with vit. $D_{2}(1,5$ and $10 \mu \mathrm{g} / \mathrm{mL})$, quercetin $(5$ and $10 \mu \mathrm{g} / \mathrm{mL})$ or cotreatment with high-dose vit. $D_{2}(5 \mu \mathrm{g} / \mathrm{mL})$ and quercetin $(1,5$ and $10 \mu \mathrm{g} / \mathrm{mL})$. S-A- $\beta$ - gal positive cells staining for evaluation of cellular senescence expressed as blue color. Arrow marks: indicates the presence of SA- $\beta$-gal staining in the yolk sac. Thin arrow marks: is an indication for the presence of intense SA- $\beta$-gal staining in the caudal (cloacal) end of the intestine. Dotted arrow marks: is an indication for the presence of SA- $\beta$-gal staining in the spinal cord. Arrowhead in blue: is an indication for the presence of SA- $\beta$-gal staining in the brain. Red circles: is an indication for the presence of SA- $\beta$-gal staining in the oesophagyus of zebrafish larvae at $120 \mathrm{hpf}$. (scale bar $=200 \mu \mathrm{m})$.

orange/ethidium bromide (AO/EB) fluorescent staining. $A O / E B$ staining has long been used to identify apoptosisassociated changes to the cell membranes during the process of apoptosis (Gherghi et al., 2003). AO/EB method can be used in an accurate way to distinguish the cells at the different stages of apoptosis (Baskić et al., 2006). Therefore, AO/EB staining can be effectively used to estimate the drug sensitivity test (DSTs). The fragmentation in the DNA absorbs and take up the ethidium bromide stain making an orange color while the other parts of the staining takes up acridine orange and emits a green fluorescence. In consistent with the cell results by other researchers, we observed that zebrafish treated with varying concentrations of highdose vit. $D_{2}(1,5$ and $10 \mu \mathrm{g} / \mathrm{mL})$ had more expression of orange-colored nuclei as an indication of dead cell becoming permeable to ethidium bromide stain which happens during apoptosis. There was also a dosedependent increase in the number of dead cells and fragmented DNA in the zebrafish larvae on vit. $D_{2}$ groups. However, co-treatment groups of vit. $D_{2}$ and quercetin showed an effective reduction in the number of apoptotic events occurring in the zebrafish larvae and further enhancing the healthy development of zebrafish larvae (Figure 7A, B). In conclusion, we observed that quercetin effectively alleviated the toxic effects of highdose vit. $D_{2}$ induced apoptotic cell death.

\section{Discussion}

Development of embryos is an organized, complex, sophisticated and puzzling process in which the changes occurring in the molecular and cellular levels are manifested through the phenotype of the organism. Evaluating the embryotoxicity and teratogenic toxicity of vitamins and compounds from therapeutic plants affecting or benefitting the development of the embryos is very important which testing the pharmacological effects of the therapeutic compounds. Zebrafish embryotoxicity study has become an indispensable tool for evaluating the toxicity and efficacy of drugs and natural compounds. We evaluated the toxicity of administering high-dose vit. $D_{2}$ in triggering aberrations during the development of zebrafish embryos. The treatment of vit. $D_{2}(1,5,10 \mu \mathrm{g} / \mathrm{mL})$ started at $6 \mathrm{hpf}$ and we treated everyday till $120 \mathrm{hpf}$. The evaluation of teratogenicity was performed every $24 \mathrm{~h}$ to evaluate morphological deformities such as delayed hatching rate, coagulation, yolk edema, pericardial edema, curved tail, curved fin, and hydrocephalus, which are the common parameters of teratogens induced abnormalities. Although vitamin $D$ is a very important fat-soluble secosteroids needed for our body to function normally, however here we report the first case of zebrafish embryotoxicity induced by high-dose vit. $D_{2}$. Through analysis of visual assessment by microscope and scoring the morphological features, we observed clear defects in the development of zebrafish embryos at 5 and $10 \mu \mathrm{g} / \mathrm{mL}$ of vit. $D_{2}$. The hatching rate and survivability rate were drastically reduced and the body length was found to be shorter and smaller at a higher dose of vit. $D_{2}$. The period of hatching is critically important during zebrafish embryogenesis and delay in the hatching rate is attributed to the different developmental abnormalities. Other parameters such as motility of zebrafish larvae also revealed that exposure 


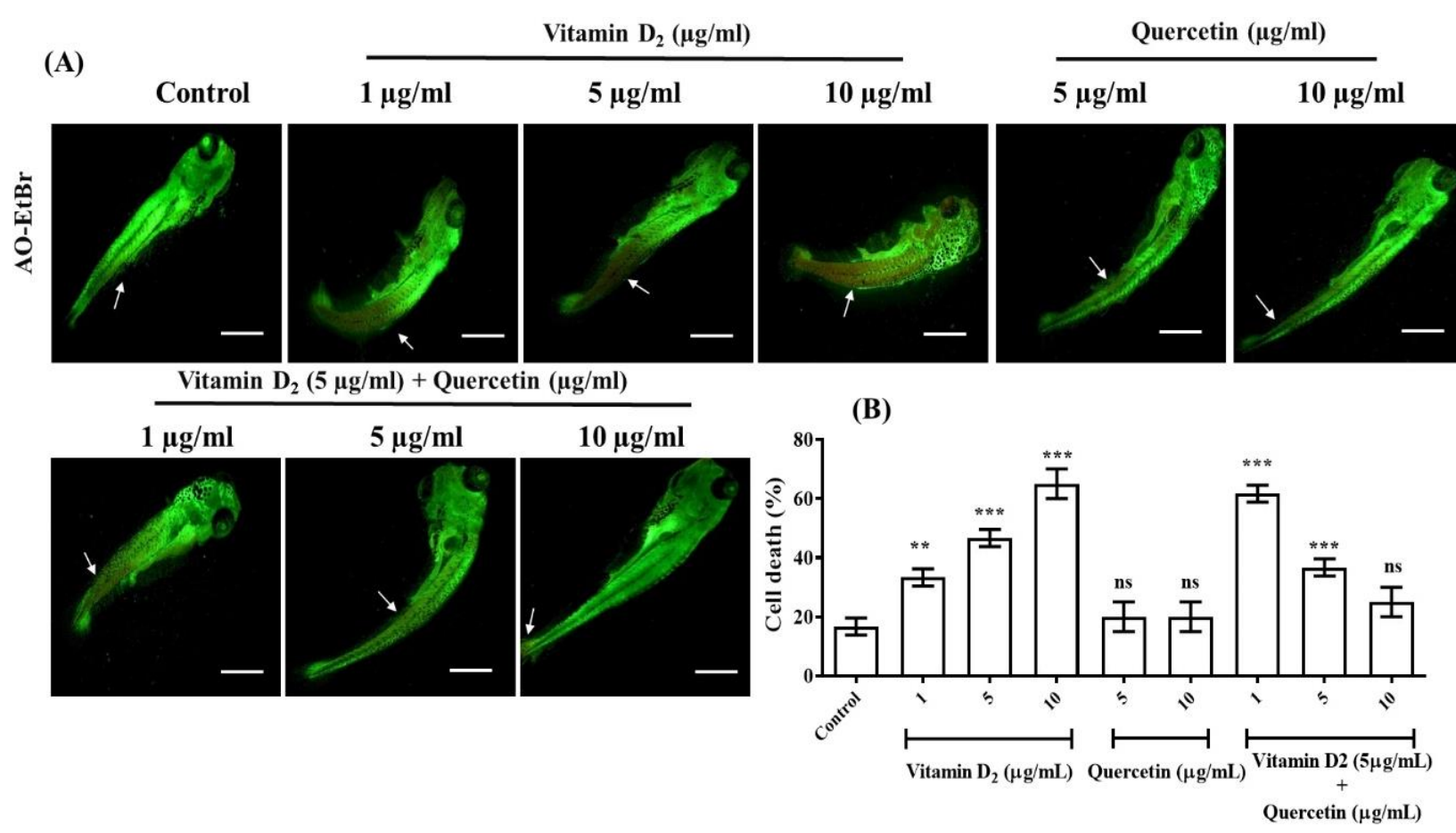

Figure 7. Estimation of cell death by acridine orange/ ethidium bromide staining after treatment with vit. $\mathrm{D}_{2}(1,5 \mathrm{and} 10 \mu \mathrm{g} / \mathrm{ml})$, quercetin $(5$ and $10 \mu \mathrm{g} / \mathrm{ml})$ or co-treatment with high-dose vit. $\mathrm{D}_{2}(5 \mu \mathrm{g} / \mathrm{ml})$ and quercetin $(1,5 \mathrm{and} 10 \mu \mathrm{g} / \mathrm{ml})$ (B) Percentage of cell death evaluated $\mathrm{AO}-\mathrm{EtBr}$ staining. Arrow: represents the regions of dead cells where ethidium bromide binds giving out an orange color. The data that are represented here are the means \pm S.D. where significant difference is indicated as $* p<0.05, * * p<$ $0.01, * * * p<0.001$ and $n s$ (non-significant), where control vs vit. $\mathrm{D}_{2}$ group, control vs Quercetin group, control vs vit. $\mathrm{D}_{2}+$ quercetin group. Statistical significance analysis was carried out through a one-way analysis of variance (ANOVA) prism.

to high-dose vit. $D_{2}$ reduced the locomotion ability, which was attributed to alteration and damage to the central nervous system (Sun et al., 2016). Another mechanism reported by other researchers is druginduced oxidative stress resulting in elevated reactive oxygen species (ROS) production and an apparent decrease in the concentration of antioxidant enzymes (Deavall et al., 2012). ROS is the key factor in promoting oxidative stress and the generated oxygen free radicals damage the biological molecules by stealing electrons. The antioxidant enzymes such as SOD, catalase, and glutathione works by neutralizing these free radicals by donating electrons and reduction in these antioxidants create an imbalance in the antioxidant system. These free radicals are the product of a normal cellular mechanism present as a single atom or as molecules containing one or more unpaired electrons in their valence shell or the outer orbit. These uneven number of free electrons makes them very unstable, short lived, and highly reactive. Hence, these free radicals can extract electrons from other molecules present in the biological system to attain stability thereby creating more instability and starting a chain reaction cascade system that finally damages the entire cells, tissues, and organs (Jones., 2008). Both ROS and reactive nitrogen species (RNS) collectively constitute the free radical species which play both the roles as being beneficial or toxic for the living system (Pham-Huy and Pham-Huy., 2008). Excessive ROS production has been found to cause damage to the integrity of the various biomolecules such as lipids (Witztum and Steinberg.,
1991), different types of proteins (Davies., 2016), and DNA (Marnett., 2000) which leads to an increase in oxidative stress causing numerous diseases such as neurodegenerative diseases, cardiovascular diseases, respiratory diseases, aging and so forth (Stadtman., 2006). We observed a sharp dose-dependent increase in the intracellular ROS production and malondialdehyde concentration in zebrafish larvae treated with high-dose vit. $D_{2}$. However, quercetin was able to significantly counteract and neutralize the generation of ROS. Similarly, we observed a slight increase in the antioxidant enzymes such as SOD and glutathione in cotreatment groups indicating that quercetin played a major role in reducing the toxicity of high-dose vit. $D_{2}$. We also observed a sharp decrease in the apoptotic cell death events in co-treated groups of zebrafish larvae. These results further elucidated the protective role of quercetin from the toxic effects of high-dose vit. $D_{2}$ in embryonic development. The findings from this study can be used to further explore the protective role of quercetin in drug-induced toxicity studies.

\section{Ethical Statement}

All the experiments procedures were performed according to the guidelines for animal care and handling norms approved by the Institutional Animal Care and Use Committee of Daegu University, Gyeongbook, South Korea (Number: Lab-2021E-164709). 


\section{Funding Information}

This work was supported by Korea Institute of Planning and Evaluation for Technology in Food, Agriculture and Forestry (IPET) through Customized Innovation Food \& Natural Relief Material Engineering Development Program (or Project), funded by Ministry of Agriculture, Food and Rural Affairs (MAFRA) (319047-3).

\section{Author Contribution}

Sun Chul Kang designed the experiment. Sukkum Ngullie Chang performed the zebrafish embryotoxicity study and wrote the manuscript. Hyun Jin Kim and Sun Chul Kang critically reviewed and approved the manuscript. All authors have read and agreed to this version of the manuscript.

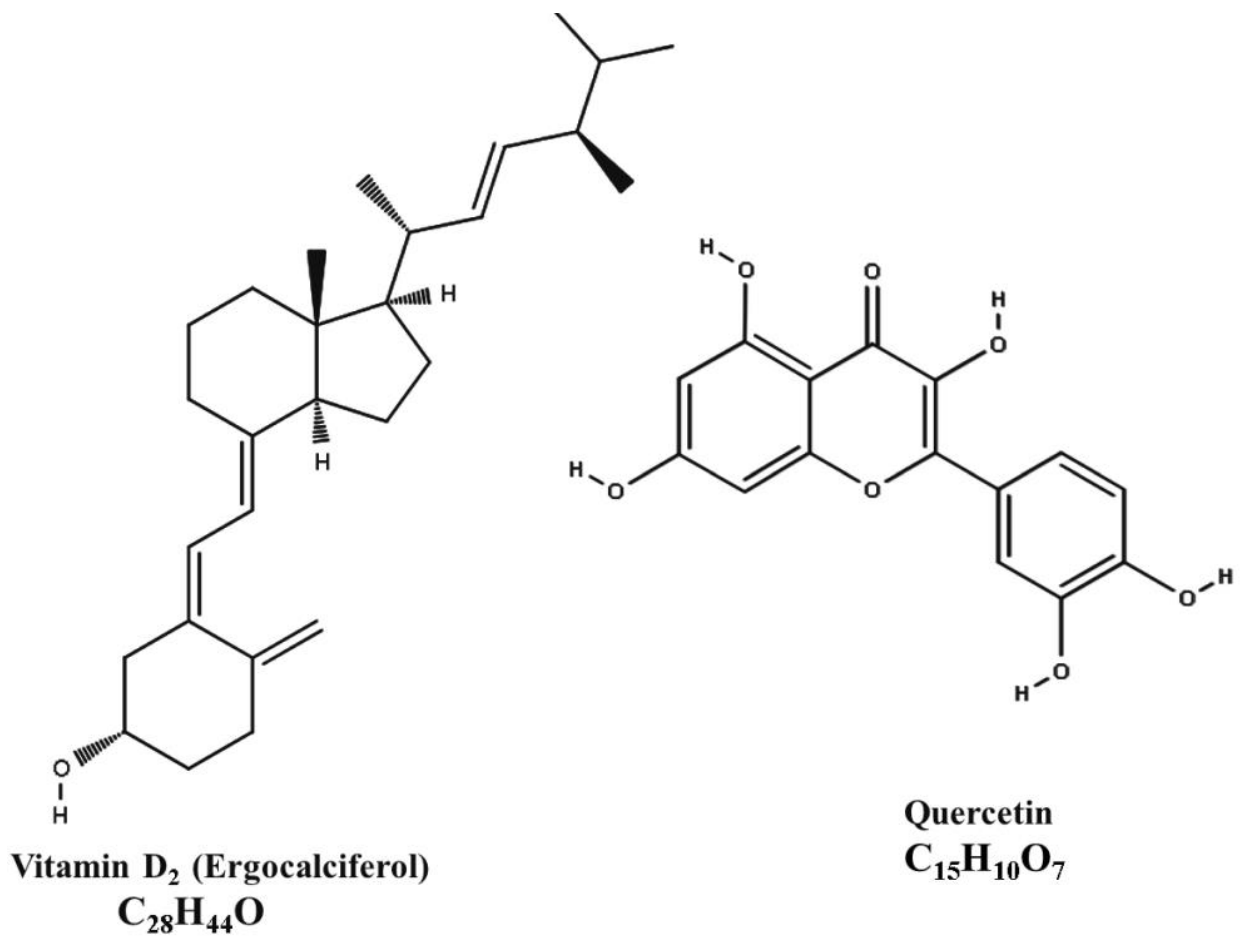

Supplementary Figure 1. Structure of vit. $\mathrm{D}_{2}$ and quercetin.

\section{Conflict of Interest}

The authors declare no conflict of interest. The funders had no role in the design of the study; in the collection, analyses, or interpretation of data; in the writing of the manuscript; or in the decision to publish the results.

\section{References}

Alvarez, M., Urbina, G., Perdomo, L. (2014). Excretion product of Shigella dysenteriae (SdyEP) induced cell death in early larval stage of Zebrafish (Danio rerio): Acridine orange and Ethidium bromide (AO/EB) in vivo staining. International Journal of Morphology vol.31, pp.11751180. https://doi.org/10.4067/S0717-95022014000100014

Baskić, D., Popović, S., Ristić, P., Arsenijević, N.N. (2006). Analysis of cycloheximide-induced apoptosis in human leukocytes: Fluorescence microscopy using annexin $\mathrm{V} /$ propidium iodide versus acridin orange/ethidium bromide. Cell Biology International 30 (11): 924-932. https://doi.org/10.1016/j.cellbi.2006.06.016

Chang, S.N., Dey, D.K., Oh, S.T., Kong, W.H., Cho, K.H., AlOlayan, E.M., Hwang, B.S., Kang, S.C., Park, J.G. (2020). Phorbol 12-myristate 13-acetate induced toxicity study and the role of tangeretin in abrogating hif-1 $\alpha$-nf-кb crosstalk in vitro and in vivo. International Journal of Molecular Sciences 21(23), 9261. https://doi.org/10.3390/ijms21239261

Chang, S.N., Khan, I., Kim, C.G., Park, S.M., Choi, D.K., Lee, H. et al. (2021b). Decursinol angelate arrest melanoma cell proliferation by initiating cell death and tumor shrinkage via induction of apoptosis. International Journal of Molecular Sciences 22(8): 4096. https://doi.org/10.3390/ijms22084096.

Chang, S.N., Kim, S.H., Dey, D.K., Park, S.M., Nasif, O., Bajpai, V.K., Kang, S.C., Lee, J.T., Park, J.G. (2021a). 5-Odemethylnobiletin alleviates ccl4-induced acute liver injury by equilibrating ros-mediated apoptosis and autophagy induction. International Journal of Molecular Sciences 22(3), 1083. https://doi.org/10.3390/ijms22031083

Chang, S.N., Lee, J.J., Kim, H.J., Kang, S.C. (2021). Quercetin enhances vitamin D2 stability and mitigate the degradation influenced by elevated temperature and $\mathrm{pH}$. Turkish Journal of Chemistry 45: 1155-1161. https://doi.org/10.3906/kim-2103-5

Choi, T.Y., Choi, T.I., Lee, Y.R., Choe, S.K., Kim, C.H. (2021). Zebrafish as an animal model for biomedical research. Experimental and Molecular Medicine 53,310-317 https://doi.org/10.1038/s12276-021-00571-5

Da Silva-Álvarez, S., Guerra-Varela, J., Sobrido-Cameán, D., 
Quelle, A., Barreiro-Iglesias, A., Sánchez, L., Collado, M. (2020). Developmentally-programmed cellular senescence is conserved and widespread in zebrafish. Aging (Albany. NY) 12(18):17895-17901 https://doi.org/10.18632/aging.103968

Davies, M.J. (2016). Protein oxidation and peroxidation. Biochemical Journal 473(7): 805-25. https://doi.org/10.1042/BJ20151227

Deavall, D.G., Martin, E.A., Horner, J.M., Roberts, R. (2012). Drug-induced oxidative stress and toxicity. Journal of Toxicology 2012: 645460. https://doi.org/10.1155/2012/645460

DeLuca, H.F. (2004). Overview of general physiologic features and functions of vitamin D. The American Journal of Clinical Nutrition 80:1689S-96S. https://doi.org/10.1093/ajcn/80.6.1689s

Dey, D.K., Chang, S.N., Gu, J.Y., Kim, K.M., Lee, J.J., Kim, T.H., et al. (2021). Ultraviolet B-irradiated mushroom supplementation increased the $\mathrm{Ca}++$ uptake and ameliorated the LPS-induced inflammatory responses in zebrafish larvae. Journal of Food Biochemistry 45(6): e13742. https://doi.org/10.1111/jfbc.13742.

Gherghi, I.C., Girousi, S.T., Voulgaropoulos, A.N., TzimouTsitouridou, R. (2003). Study of interactions between DNA-ethidium bromide (EB) and DNA-acridine orange $(A O)$, in solution, using hanging mercury drop electrode (HMDE). Talanta. Volume 61, Issue 2, Pages 103-112. https://doi.org/10.1016/S0039-9140(03)00238-8

Goessling, W., Sadler, K.C. (2015). Zebrafish: An Important Tool for Liver Disease Research. Gastroenterology 149(6):1361-77. https://doi.org/10.1053/j.gastro.2015.08.034

Harishkumar, R., Reddy, L.P.K., Karadkar, S.H., Murad, M. Al, Karthik, S.S., Manigandan, S., Selvaraj, C.I., Christopher, J.S.G., (2019). Toxicity and selective biochemical assessment of quercetin, gallic acid, and curcumin in zebrafish. Biol. Pharm. Bull. 42, 1969-1976 https://doi.org/10.1248/bpb.b19-00296

Harwood, M., Danielewska-Nikiel, B., Borzelleca, J.F., Flamm, G.W., Williams, G.M., Lines, T.C. (2007). A critical review of the data related to the safety of quercetin and lack of evidence of in vivo toxicity, including lack of genotoxic/carcinogenic properties. Food and Chemical Toxicology 45, 2179-2205 https://doi.org/10.1016/j.fct.2007.05.015

Ishidate, M., Sofuni, T., Yoshikawa, K., Hayashi, M., Nohmi, T., Sawada, M., Matsuoka, A., (1984). Primary mutagenicity screening of food additives currently used in Japan. Food and Chemical Toxicology 22 (8), 623-636. https://doi.org/10.1016/0278-6915(84)90271-0

Jäpelt, R.B., Jakobsen, J. (2013). Vitamin D in plants: A review of occurrence, analysis, and biosynthesis. Frontiers in Plant Science 4:136. https://doi.org/10.3389/fpls.2013.00136

Jeon, H.J., Kim, K., Kim, Y.D., Lee, S.E., 2019. Antimelanogenic activities of piperlongumine derived from Piper longum on murine B16F10 melanoma cells in vitro and zebrafish embryos in vivo: its molecular mode of depigmenting action. Applied Biological Chemistry 62, 61. https://doi.org/10.1186/s13765-019-0468-7

Jones, D.P. (2008). Radical-free biology of oxidative stress. The American Journal of Physiology-Cell Physiology 295(4):C849-68.

https://doi.org/10.1152/ajpcell.00283.2008

Kamel, M., Ninov, N. (2017). Catching new targets in metabolic disease with a zebrafish. Current Opinion in Pharmacology 37:41-50.

https://doi.org/10.1016/j.coph.2017.08.007

Kithcart, A., MacRae, C.A. (2017). Using Zebrafish for HighThroughput Screening of Novel Cardiovascular Drugs. JACC: Basic to Translational Science Volume 2, Issue 1, Pages 1-12. https://doi.org/10.1016/j.jacbts.2017.01.004

Li, J., Zhang, Y., Liu, K., He, Q., Sun, C., Han, J., Han, L., Tian, Q. (2018). Xiaoaiping induces developmental toxicity in Zebrafish Embryos through activation of ER stress, apoptosis and the wnt pathway. Frontiers in Pharmacology 9:1250. https://doi.org/10.3389/fphar.2018.01250

Marnett, L.J. (2000). Oxyradicals and DNA damage. Carcinogenesis 21(3):361-70. https://doi.org/10.1093/carcin/21.3.361

Nölle, N., Argyropoulos, D., Müller, J., Biesalski, H.K. (2018). Temperature stability of vitamin D2 and color changes during drying of UVB-treated mushrooms. Drying Technology Volume 36, pages 307-315. https://doi.org/10.1080/07373937.2017.1326501

Pham-Huy, L.A., He, H., Pham-Huy, C. (2008). Free radicals, antioxidants in disease and health. International Journal of Biomedical Science 4(2): 89-96.

Roper, C., Tanguay, R.L. (2018). Zebrafish as a model for developmental biology and toxicology, in: Handbook of Developmental Neurotoxicology second edition 143151.

https://doi.org/10.1016/B978-0-12-809405-1.00012-2

Shams, S., Rihel, J., Ortiz, J.G., Gerlai, R. (2018). The zebrafish as a promising tool for modeling human brain disorders: A review based upon an IBNS Symposium, in: Neuroscience and Biobehavioral Reviews. Volume 85, Pages 176-190.

https://doi.org/10.1016/j.neubiorev.2017.09.002

Stadtman, E.R. (2006). Protein oxidation and aging. Free Radical Research 40(12):1250-8. https://doi.org/10.1080/10715760600918142

Sultana, B., Anwar, F. (2008). Flavonols (kaempeferol, quercetin, myricetin) contents of selected fruits, vegetables and medicinal plants. Food Chemistry 108(3):879-84. https://doi.org/10.1016/j.foodchem.2007.11.053

Sun, Y., Zhang, G., He, Z., Wang, Y., Cui, J., Li, Y. (2016). Effects of copper oxide nanoparticles on developing zebrafish embryos and larvae. International Journal of Nanomedicine 2016:11 905-918. https://doi.org/10.2147/IJN.S100350

Thirumurthi, N.A., Raghunath, A., Balasubramanian, S., Perumal, E. (2021). Evaluation of Maghemite Nanoparticles-Induced Developmental Toxicity and Oxidative Stress in Zebrafish Embryos/Larvae. Biological Trace Element Research. https://doi.org/10.1007/s12011-021-02830-y

Tugcu, G., Charehsaz, M., Aydın, A. (2019). Toxicological evaluation of ergocalciferol, cholecalciferol, and their metabolites by a category approach. Drug and Chemical Toxicology 14;1-7. https://doi.org/10.1080/01480545.2019.1650061

Vasamsetti, B.M.K., Kim, N.S., Chon, K., Park, H.H. (2020). Teratogenic and developmental toxic effects of etridiazole on zebrafish (Danio rerio) embryos. Applied Biological Chemistry 63, 80.

https://doi.org/10.1186/s13765-020-00566-2 
Villiard, É., Denis, J.F., Hashemi, F.S., Igelmann, S., Ferbeyre, G., Roy, S. (2017). Senescence gives insights into the morphogenetic evolution of anamniotes. Biology Open 6(6):891-896. https://doi.org/10.1242/bio.025809

Witztum, J.L., Steinberg, D. (1991). Role of oxidized low density lipoprotein in atherogenesis. Journal of Clinical Investigation volume 126, Pages 1053S-1057S. https://doi.org/10.1172/JCI115499

Yang, D., Wang, T., Long, M., Li, P. (2020). Quercetin: Its Main
Pharmacological Activity and Potential Application in Clinical Medicine. Oxidative Medicine and Cellular Longevity 2020, 8825387. https://doi.org/10.1155/2020/8825387

Yuan, X., Lee, J., Park, E., Lee, H.K., Kim, J.H. (2021). Toxicometabolomics of lindane in adult zebrafish (Danio rerio) using GC-MS/MS and LC-Orbitrap-MS/MS. Applied Biological Chemistry 64, 52.

https://doi.org/10.1186/s13765-021-00623-4 